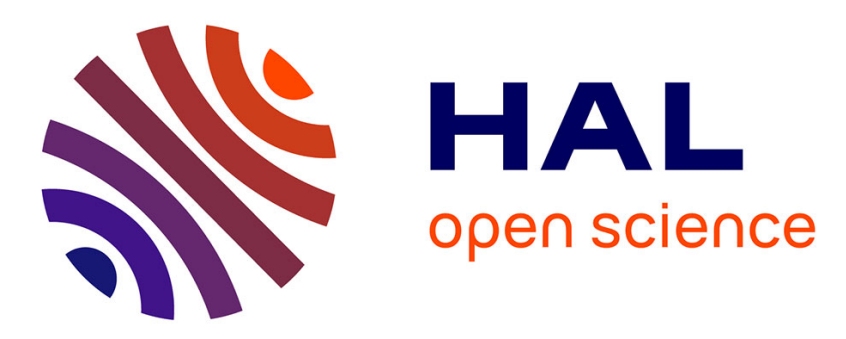

\title{
High Performance Thermoplastic Composite from Flat-knitted Multi-layer Textile Preform using Hybrid Yarn
}

\author{
Md. Abounaim, Olaf Diestel, Gerald Hoffmann, Chokri Cherif
}

\section{- To cite this version:}

Md. Abounaim, Olaf Diestel, Gerald Hoffmann, Chokri Cherif. High Performance Thermoplastic Composite from Flat-knitted Multi-layer Textile Preform using Hybrid Yarn. Composites Science and Technology, 2011, 71 (4), pp.511. 10.1016/j.compscitech.2010.12.029 . hal-00723644

\section{HAL Id: hal-00723644 \\ https://hal.science/hal-00723644}

Submitted on 12 Aug 2012

HAL is a multi-disciplinary open access archive for the deposit and dissemination of scientific research documents, whether they are published or not. The documents may come from teaching and research institutions in France or abroad, or from public or private research centers.
L'archive ouverte pluridisciplinaire HAL, est destinée au dépôt et à la diffusion de documents scientifiques de niveau recherche, publiés ou non, émanant des établissements d'enseignement et de recherche français ou étrangers, des laboratoires publics ou privés. 


\section{Accepted Manuscript}

High Performance Thermoplastic Composite from Flat-knitted Multi-layer Textile Preform using Hybrid Yarn

Md. Abounaim, Olaf Diestel, Gerald Hoffmann, Chokri Cherif

PII:

S0266-3538(10)00516-6

DOI:

10.1016/j.compscitech.2010.12.029

Reference:

CSTE 4894

To appear in:

Composites Science and Technology

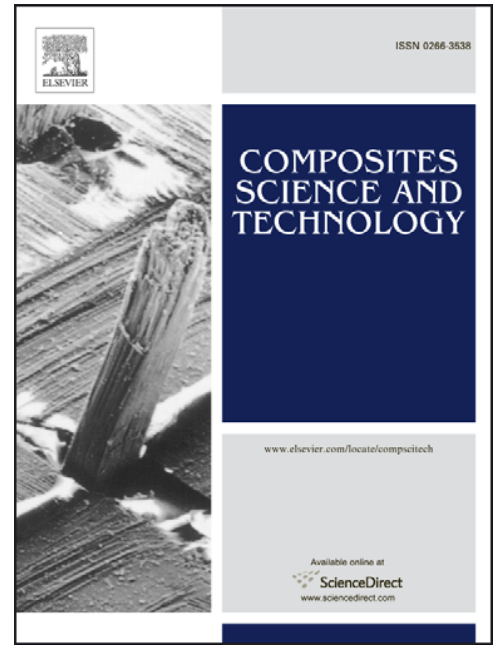

Received Date: $\quad 18$ June 2010

Revised Date: $\quad 29$ November 2010

Accepted Date: $\quad 22$ December 2010

Please cite this article as: Abounaim, Md., Diestel, O., Hoffmann, G., Cherif, C., High Performance Thermoplastic Composite from Flat-knitted Multi-layer Textile Preform using Hybrid Yarn, Composites Science and Technology (2010), doi: 10.1016/j.compscitech.2010.12.029

This is a PDF file of an unedited manuscript that has been accepted for publication. As a service to our customers we are providing this early version of the manuscript. The manuscript will undergo copyediting, typesetting, and review of the resulting proof before it is published in its final form. Please note that during the production process errors may be discovered which could affect the content, and all legal disclaimers that apply to the journal pertain. 


\title{
High Performance Thermoplastic Composite from Flat- knitted Multi-layer Textile Preform using Hybrid Yarn
}

\author{
Md. Abounaim, Olaf Diestel, Gerald Hoffmann, Chokri Cherif \\ Institute of Textile Machinery and High Performance Material Technology (ITM), \\ Technische Universität Dresden, Hohe Strasse 6, 01069 Dresden, Germany
}

\begin{abstract}
Modern flat knitting machines using high performance yarns are able to knit fabrics including the reinforcement yarns arranged differently into knit structures. Due to their improved mechanical properties, composites made from multi-layer knit fabrics show great potential in lightweight applications. This paper reports on the development of flat knitted multi-layer textile preforms for high performance thermoplastic composites using hybrid yarns made of glass (GF) and polypropylene (PP) filaments. Such textile preforms with different reinforcements were used to consolidate into $2 \mathrm{D}$ thermoplastic composites. Moreover, the mechanical properties of these composites were studied. The mechanical properties of $2 \mathrm{D}$ composites were found to be greatly affected by different arrangements of reinforcement yarns. The integration of reinforcement yarns as biaxial inlays (warp and weft yarns) is found to be the best solution for knitting, whereas tuck stitch shaped and unidirectional arranged reinforcements offer also promising application possibilities.
\end{abstract}

Key words: A. Textile composites; B. Mechanical property; E. Knitting

\footnotetext{
"Corresponding author: e-mail: abounaim@ itb.mw.tu-dresden.de; Tel: 004917622151327
} 


\section{Introduction}

Textile reinforced composites are fiber-reinforced composites whose unit reinforcement structures are characterized by the fiber orientation. Unlike the conventionally used isotropic materials, textile reinforced composites can be specifically customised in terms of their material properties for particular loading situations by modifying the fibre architecture and material combinations. These composites are best suited for any design program that demands weight savings, precision engineering, finite tolerances, and the simplification of parts in both production and operation. Textile reinforced composite is considered to be cheaper, faster, and easier to manufacture than cast aluminium or steel artefact, and maintains similar and sometimes better tolerances and material strengths. The potential applications of these composites are the lightweight industries, especially in air and spacecrafts, transport vehicles, combat vehicles, lift cabins, mechanical engineering, architectural designs, marine applications and infrastructures, etc [1-4].

Thermoplastic composites are comprised of at least one reinforcement material and a thermoplastic polymer as matrix. These composites show distinct advantages over thermoset composites. Due to their high fracture toughness, easy recycling, elongation, short processing time, various forming possibilities, weld-ability, low cost and resistance to medias and corrosion, they appear to be more promising for industrial applications $[1-3,7,10-12,15]$. However, conventional thermoplastic composite manufacturing routes are two stage processes. Firstly, a precursor material is formed, for example, commingled fibers, prepregs, powder impregnated tows, fiber Impregnated thermoplastic, short and long fiber reinforced polymer pellets etc. The secondary process is forming the component into the final product applying high pressure and high temperature. The aim of the aforementioned process is to coat the reinforcing fibers in thermoplastic and form the desired shape. Nevertheless, 
commingled hybrid yarns consisting of reinforcement and matrix filaments are soft, flexible, drapeable and are available at low cost, which makes them a forerunner for thermoplastic composite applications. The reinforcement component of the hybrid yarn is generally high performance fibers such as glass, carbon and aramid fibers. Glass fibers are used extensively due to the optimized cost versus mechanical performances. The thermoplastic matrix is used to fix the reinforcement components in a defined order for better bearing of applied forces by, to ensure good adhesion between the fibers and matrix material and to develop low cost products, especially for the automobile industries. The use of glass (GF) and polypropylene (PP) filaments in hybrid yarn in a volume combination of $52 \%$ and $48 \%$ respectively is reported to optimize the mechanical properties of textile reinforced thermoplastic composites [1$4,7,9-16]$.

Textiles generally produced by braiding, weaving and other unidirectional techniques are used for composites because of their excellent mechanical properties, such as high strength, stiffness and damage tolerance in impact loading. Knitted composites, however, exhibit greater drapability and higher impact resistance as compared to the above-mentioned textile based composites. Moreover, knitting is considered as one of the most economical textile manufacturing process. Nevertheless, knitted composites are generally considered to have inferior mechanical properties due to their highly looped fiber architecture. Conversely, the integration of reinforcement yarns into the knit structures is inevitable in order to improve the mechanical properties for the application in high performance composites [1-13].

Modern electronic flat knitting machines are capable of manufacturing $2 \mathrm{D}$ or $3 \mathrm{D}$ complex shaped engineering structures. Unique technical features which allow rapid and complex production include individual needle selection capability, the presence of holding down sinkers, presser-foots, racking, transfer, adapted feeding devices 
combined with CAD system and modern programming installations. Furthermore, the flexibility of the knitting process in combination with the possibility of integration of reinforcement yarns into fabric structures is capturing the attention of many researchers. Moreover, the flexible yarn feeding system and the improved yarn tensioning together with the optimized knitting process enable effortless knitting of high rigidity, a high friction coefficient and the brittleness of the glass filaments [1-12]. The mechanical properties of thermoplastic flat knitted composites are not only dependent on the hybrid yarns used, but are also greatly affected by the knit structures as well as the orientation of the reinforcement yarns [16-19]. Knit fabrics could be reinforced by integrating the reinforcement yarns into the fabrics as knit loops, tuck stitches, weft and warp inlays or combinations of them. However, the mechanical properties of such knit composites could be manipulated in higher extend on the basis of the fibers orientation as well as their damages made by the integration methods in knitting [20-22].

One goal of the research program "Textile-reinforced composite components for function-integrating multi-material design in complex lightweight applications" funded by the German Research Foundation (SFB 639) at the Technische Universität Dresden, is to develop reinforced textile preforms using hybrid yarns on flat knitting machine for high performance composite application. In order to achieve this objective, knitted fabrics were produced successfully on modern flat knitting machine using exemplar GF-PP hybrid yarns. The reinforcement yarns were integrated differently in the fabric structures in order to not only check the possibility of integration of reinforcement yarns by flat knitting, but also to investigate the effect of fiber orientations on the mechanical properties of composites. The integration of reinforcement yarns in the fabric structures were, for instance, as knit loops; tuck stitches; weft yarns; warp yarns; warp yarns and tuck stitches; warp and weft yarns; 
weft and warp yarns including with tuck stitches. In the next stage, 2D composites were produced from these knitted preforms and mechanically investigated.

\section{Experimental Study}

\subsection{Materials}

Hybrid yarns consisting of glass (volume: 52 percent) and polypropylene filaments (volume: 48 percent) were used as high performance and thermoplastic materials respectively. These hybrid yarns were developed as well as manufactured at the Institute of Textile Machinery and High Performance Material Technology (ITM) of Technische Universität Dresden (Germany) using the modified polypropylene filaments "Prolen $\mathrm{H}$ " by the Chemosvit Fibrochem a.S. Company of Slovakia and the glass filaments by the P-D Glasseiden GmbH Oschatz Company of Germany. Hybrid yarns of 138 tex were selected as the knitting yarns for base fabrics (base loop yarn), whereas 1200 tex (three ply of 400 tex) was the reinforcement yarn.

\subsection{Flat Knitting Machine}

Knitting was carried out on the modern electronic flat knitting machine CMS 320 TC of company H, Stoll G mbH \& Co. KG, Reutlingen of Germany and Steiger Aries 3 of company Steiger SA of Switzerland. Flat knitting machine carries the carriage which is mounted on both needle beds and holds the cams for the activation of needles for knitting. Usually, knitting is followed on both needle beds (arranged in V-shaped) separately when the carriage is traversed over them. However, Steiger Aries 3 flat knitting machine offers the open carriage in which warp yarns could be delivered to the knitting zone for multi-layer knitting. 


\subsection{Integration of reinforcement yarns by flat knitting}

Reinforcement yarns were integrated in knit structure as knit loops, tuck stitches and as weft yarns on the flat knitting machine CMS $320 \mathrm{TC}$ of company H. Stoll G mbH \& Co. KG. However, reinforcement yarns were integrated in the fabric structures as warp yarns; warp yarns and tuck stitches; warp and weft yarns; warp and weft yarns along with tuck stitches on the flat knitting machine Steiger Aries 3 of company Steiger SA. The needle gauge was selected 7 needles per inch. The manufacturing details of these knit structures are presented in Fig. 1 and Fig 2. Additionally, fabric details are presented in Table 1.

\subsection{Manufacturing the thermoplastic composites using knit fabrics}

Composites were produced from knit fabrics on the laboratory hot-pressing machine (COLLIN P300 PV, Dr. Collin GmbH, Germany). Temperature and pressure flowcharts, along with the used mechanical tools for $2 \mathrm{D}$ molding are shown in Fig. 3. At first, knit fabrics were put into the press at room temperature and the pressure was applied to 9 bars. The temperature was then raised at the rate of $10^{\circ} \mathrm{C}$ per minute until $221^{\circ} \mathrm{C}$ was reached for the melting of the polypropylene. After 6 minutes at $221^{\circ} \mathrm{C}$ a pressure of 52 bars was applied (oscillating) and this temperature was kept for 10 minutes. Finally, the temperature was dropped down to room temperature keeping the pressure constant. Table 1 and Fig. 1-2 present details of knit fabrics that were used to fabricate composites.

\subsection{Measuring the Mechanical Properties of 2D Composites}

Tensile and flexural testing was performed on Zwick Z100 strength testing machine. The machine uses the four point loading method for testing the flexural strengths of the specimens. The testing was performed according to test standards DIN EN ISO 
527-4 for tensile and DIN EN ISO 14125 for flexural strength. The impact tests were carried out with the aid of a pendulum arm type impact tester, which functions based on the principle of Charpy Impact Test technique. Testing was carried out at the Institute of Lightweight Engineering and Polymer Technology (ILK) at the TU Dresden (Germany). Standard methods of sampling and testing were applied as stated in DIN EN ISO 179-2. However, the glass filament volume fractions of all composites were measured by the burning test and they are unlike for different composites. The measured glass filament volume fractions of all composites have already been documented in Table 1. The cause of such dissimilar fiber volume fractions is the divergent orientation of reinforcing fibers in the knitted structures achieved by the innovative integration concepts of reinforcement yarns based on flat knitting. Therefore, the constant amount of fiber volume fractions in all samples was not predetermined before while developing the flat knitted innovative textile preforms, since the fiber volume fraction is subjected to be changed by the diverse orientation methods. Consequently, the aim is also to compare the mechanical properties of different knit composites considering their respective fiber orientations as well as fiber-damages by the different integration concepts of reinforcement yarns developed within this research work.

\section{Results and Discussion}

\subsection{Tensile Properties of 2D Composites}

The tensile properties of composites produced from different knit fabrics have been presented in Fig. 4 ( $a, b, c, d)$. The tensile properties in both directions improve from composites with knit loops $(K)$ to tuck stitches $(T)$, whereas these properties are maximum only in course direction for weft yarns (W). But, these tensile properties were recorded very improved in both wales and course directions (in $0^{\circ} \& 90^{\circ}$ ) for 
knit fabric with reinforcement yarns integrated as weft and warp inlays (WWA). However, tensile properties are found very improved in level especially in wales direction for knit fabrics type WA, WAT and WWAT in which the reinforcement yarns were integrated as warp inlays with different course directional reinforcements. The variation of tensile properties in wales direction among the above mentioned fabric types could be well explained by the dissimilar values of wales per centimetre caused by different course directional forces of respective knit structures. However, among them only the knit structure WWAT shows few improvements in tensile testing especially in course direction because of the presence of weft inlays along with tuck stitch shaped course directional reinforcement yarns. On the other hand, this effect is not found enhanced than that of tuck stitches $(T)$ due to the lower number of courses per centimetre (Table 1). Along with the reduction in glass filament breakage when knitted, the full orientation of reinforcement yarns as weft and warp inlays (non-crimp yarns) are cause for such superior tensile properties in wales and course directions of composites with reinforcement yarns as weft and warp inlays (WWA). However, the lower tensile properties were recorded for the composites with tuck stitches ( $T$ ) and knit loops $(\mathrm{K})$ even having higher glass fiber volume fractions $(45.20 \%$ and $52.5 \%$ respectively). Such effect of inferior tensile properties can be surmised as the product of the so-called curvilinear shapes of reinforcement yarns which seem to cause damage to the reinforcing glass filaments and a lack of proper fiber orientation. According to the comparison of the above results, the tensile properties of different thermoplastic knit composites are influenced mostly by the orientation as well as breakages of reinforcing components due to knitting, where the influence of fiber volume fraction is found not worth mentioning. 


\subsection{Flexural Properties of 2D Composites}

Keeping in view the analysis of flexural properties from Fig. 5 (a, b, c, d), the overall comparison of the knit structures can be ranked as most advantageous only in the wales direction for composites with reinforcement warp yarns (WA), with warp yarns along with tick stitches (WAT), as most advantageous only in the course direction for composites with reinforcement weft yarns (W) and in both directions for composites with reinforcement warp and weft yarns (WWA) respectively. However, knit structures can also be ordered as modestly advantageous in the both direction for composites with tuck stitches (T) and with biaxial inlays along with tuck stitches (WWAT). On the other hand, very inferior flexural properties were recorded in both directions for composites with reinforcement yarns as knit loops $(K)$, in wales direction for weft yarns (W), in course direction for composites with warp yarns (WA) and for warp yarns together with tuck stitches (WAT). These effects are endorsed by the already mentioned combined effect of orientation and damage of reinforcement glass filaments, whereas the variation of volume fractions of glass filaments is remained again as secondary influencing factor.

\subsection{Impact Properties of 2D Composites}

On the other hand, the results pertaining to the impact testing do not exhibit the same trends. The Fig. 6 ( $a, b, c, d)$ elaborates the measured trends. The maximum impact strength and energy absorption were recorded for weft yarns (W) and warp yarns (WA) in fiber orientated course and wales directions respectively as usual, whereas tuck stitches $(T)$ in course direction show better impact properties nearly equal to the weft yarns. However, for the composites with biaxial inlays (WWA) these properties are not as significant as they were in tensile and flexural testing. Nevertheless, Integration of reinforcement yarns as knit loops $(K)$, which caused to a higher volume 
fraction of reinforcing component in knit composite (about $52.50 \%$ ), showed also good resistance against impact in both wales and course directions even having the maximum level of glass filament breakages due to knit loop shaped orientation and these impact properties are nearby equal to the results of biaxial inlays (WWA). Conversely, knit structures WAT and WWAT showed the same tendency of results as they were in tensile and flexural testing. From the above results a view point could be forwarded, with the impact of impactor, the specimens experience slow displacements and contact forces reach their maximum levels due to good toughness in course direction of composites with reinforcement yarns as weft yarns (W), tucks stitches ( $T$ ) and in wales direction of warp yarns (WA) respectively. Generally, composites absorb energy during fracture mechanisms like delamination, shear cracking and filaments breakage. The presence of reinforcement filaments resists the deformation of the specimens leading to improved impact strength and energy absorption in filaments direction. Moreover, it is assumed that along with the damages of the reinforcement glass filaments by knitting the orientation of reinforcement filaments contribute the performance of a knit structure against impact. Consequently, improved impact properties were recorded in case of the fabric structures with the integration of reinforcement yarns as curvilinear knit loops $(K)$ and tuck stitches $(T)$, whereas the higher courses per centimetre and higher wales per centimetre along with full orientation of filaments caused the superior impact properties in course and wales directions for the knit structures with weft yarns (W) and warp yarns respectively. Based on the above analysis, it could be presumed that, the impact properties of thermoplastic knit composites are the resultant effect of the product of orientation, damage (breakage) as well as volume fraction of reinforcing glass filaments. Nevertheless, beside the anisotropic behaviour of composites consolidated from innovative knitted preforms the overall impact performance is 
expected to be much more informative. Consequently, further research is going on (for example, the drop weight test) in order to evaluate the impact properties more specifically and this result would be published very soon.

Considering the analysis of the mechanical properties of $2 \mathrm{D}$ composites showed in Fig. 4-6 and in Table 2, the integration of reinforcement yarns as multi-layer biaxial inlays (WWA) into knit fabric could be ranked as the most effective method, especially for very improved tensile and flexural properties as well as moderately improved impact properties in both wales and course directions. In addition, impact properties could be improved by introducing the tuck stitch shaped knit fabric ( $T$ ) together with the biaxial reinforced knit fabric (WWA) as multi-layers in consolidation process. However, Knit fabrics with the reinforcement yarns integrated as only weft yarns (W) and only warp yarns (WA) are in fact the unidirectional reinforced knit structures and offer superior mechanical properties only in the respective reinforcement directions (in course direction for knit structure $\mathrm{W}$ and in wales direction for knit structure WA). These unidirectional reinforced knit fabrics could replace the conventional yarn-winding technique for the manufacturing of unidirectional reinforced composites. Furthermore, these unidirectional reinforced knit fabrics could be assembled in different directions as multi-layers in consolidation process to produce multi-directional reinforced composites. On the other hand, the integration of reinforcement yarns as tuck stitches could be the substitute method for the medium level of mechanical properties if the multi-layer biaxial reinforcements are not possible. Nevertheless, the knit structures WAT and WWAT are significant only in the wales direction. 


\section{Conclusion}

Reinforced textile preforms were produced successfully on the flat knitting machines using GF-PP hybrid yarns for thermoplastic composites. Reinforcement yarns were productively integrated into the knit fabric structures individually as knit loops; tuck stitches; weft yarns; warp yarns; warp yarns and tuck stitches; weft and warp yarns; weft and warp yarns along with tuck stitches. 2D composites were produced from these knitted preforms and investigated mechanically. The mechanical properties of 2D composites were seemed to be greatly affected by different arrangements of reinforcement yarns. Tensile and flexural properties were measured and found mostly influenced by the orientation as well as the damages of reinforcing fibers by knitting. These properties were superior in the course direction for weft yarns, in the wales direction for warp yarns and in both course and wales directions for biaxial inlays. In contrast, greatly improved impact properties were documented in the fiber oriented course direction for weft yarns, for tuck stitches and in the fiber oriented wales direction for warp yarns. However, exceeding the influence of fiber orientation and damages, the fiber volume fraction in composite played also very important roles on the level impact properties. Hence, the integration of reinforcement yarns as biaxial inlays into knit fabric seems to be the most effective method. Since tuck stitch shaped structure is suitable for more energy absorption in impact, it could be mixed as in layers together with biaxial reinforced knit structures for superior mechanical properties in high performance composite applications. Nevertheless, the unidirectional reinforced knit structures (weft or warp inlays) could be used potentially as textile preforms in multi-directional reinforced composite manufacturing if the layers are arranged asymmetric in consolidation. Thermoplastic composites using flat knitted multi-layer preforms using hybrid yarns are expected to be promising in high performance lightweight applications. 


\section{Acknowledgement}

This article presents a portion of the results of the research program "Textilereinforced composite components for function-integrating multi-material design in complex lightweight applications" of the German Research Foundation (SFB 639, TP $A 2 \& A 3)$ at the Technische Universität Dresden. The authors would like to thank the Foundation for their financial support.

\section{References}

1. Abounaim, M, Hoffmann, G, Diestel, 0 , and Cherif, C, Thermoplastic Composite from Innovative Flat Knitted 3D Multi-layer Spacer Fabric Using Hybrid Yarn and the Study of 2D Mechanical Properties, Comp Sci and Tech, 2010 (70): 363-370.

2. Abounaim M, Hoffmann G, Diestel O, Cherif C. Development of flat knitted spacer fabrics for composites using hybrid yarns and investigation of 2D mechanical properties. Text Res J 2009; 79(7): 596-610.

3. Abounaim M, Hoffmann G, Diestel $O$, Cherif $C$. 3D Spacer fabric as sandwich structure by flat knitting for composites using hybrid yarn, AUTEX World Textile Conference. Izmir. Turkey: 2009. p. 675-681.

4. Abounaim M, Hoffmann G, Diestel O, Cherif C. Flat-knitted "spacer fabrics" with hybrid yarns for composite materials, Melliand Textileb 2008; 3-4: 87-89 \& E30-31.

5. Hong H, Araujo M, Fangueiro R. 3D Technical Fabrics, Knit Int 1996; 1232: 55-57.

6. Araujo MD, Hong H, Fangueiro R, Ciobanu O, Ciobanu L. Developments in WeftKnitting Technical Textiles, $1^{\text {st }}$ Autex Conference: TECHNITEX, Portugal: 2001 (1). P. 253-262.

7. Abounaim M. Modelling of technical bindings and manufacturing of flat knitted and woven "spacer fabrics" with hybrid (GF/PP) yarn as sandwich structure. Master 
Thesis no.-1310, Technische Universität Dresden, Department of Mechanical Engineering, 2006.

8. Ciobanu L. SANDTEX - Developments on knitted sandwich fabrics with complex shapes, $1^{\text {st }}$ Autex Conference: TE CHNITEX, Portugal: 2001 (1). P. 490-496.

9. Ünal A, Hoffmann G, Cherif C. Development of weft knitted spacer fabrics for composite materials, Melliand Textileb 2006; 4: 224-226 \& E49-50.

10. Torun AR, Paul C, Hanusch J, Diestel O, Hoffmann G, Cherif C. Reinforced weft knitted preforms and spacer fabrics as well as woven spacer fabrics made of commingled hybrid yarns for RP. Techtextil Symposium, Frankfurt, Germany, 12.06. - 14.06.2007.

11. Cherif C, Rödel H, Hoffmannn G, Diestel O, Herzberg C, Paul C, Schulz C, Großmann K, Mühl A, Mäder $E$, Brünig $H$. Textile Verarbeitungstechnologien für hybridgarnbasierte komplexe Preformstrukturen (Textile manufacturing technologies for hybrid based complex preform structures). Kunststofftechnik (J. Plast. Tech.) 2009; 2: 103-129.

12. Collaborative Research Centre SFB 639, Textile-reinforced composite components for function-integrating multi-material design in complex lightweight applications, Technische Universität Dresden, Germany, retrieved on $30^{\text {th }}$ of May, 2010 from http://www.tu-dresden.de/mw/ilk/sfb639/sfb_en.html.

13. Badawi S S A M. Development of the Weaving Machine and 3D Woven Spacer Fabric Structures for Lightweight Composites Materials. PhD Thesis, Technische Universität Dresden, Department of Mechanical Engineering, 2007.

14. Lin S, Modler KH, Hanke U. The application of Mechanisms in Producing TextileReinforced Thermoplastic Composite. Machine Design and Research 2008; 24: 380384. 
15. Alagirusamy R, Ogale V. Commingled and Air J et-textured Hybrid Yarns for Thermoplastic Composites. J Ind Text 2004; 33 (4): 223-243.

16. Fujita A, Maekawa Z, Hamada H. Mechanical behaviour and fracture mechanism of thermoplastic composites with commingling yarn. J Rein Plat Comp 1993; 12: $156-172$.

17. Dev VRG, Swarna A, Madhusoothanan M. Mechanical Properties of Knitted Composites using Glass Ply Yarns. J Rein PI Comp 2005; 25: 1425-1435.

18. Gommers B, Verpoest I, Houtte V. Analysis of knitted fabric reinforced composites: Part 1. Fibre orientation distribution. Comp Part A 1998; 29A: 15791588.

19. Padaki NV, Alagirusamy R, Sugun BS. Knitted preforms for composite application. J Ind Text; 35 (4): 295-321.

20. HU H, Zhu M. A study of the degree of breakage of glass filament yarns during the weft knitting process. AUTEX Res J 2005; 5(3): 141-148.

21. Lau K, Dias T. Knittability of High-modulus Yarns. J Text Inst 1994; 85 (2): 173190.

22. Savci S, Curiskis JI, Pailthorpe M. Knittability of Glass Fiber Weft-Knitted Preforms for Composites. Tex Res J 2001; 71 (1): 15-21. 
Fig. 1. Knitting technique, knit architecture, knit fabric and composite of different integration methods of reinforcement yarns (e.g. knit loops; tuck stitches; weft yarns; warp yarns).

Fig. 2. Knitting technique, knit architecture, knit fabric and composite of different integration methods of reinforcement yarns (e.g. warp yarns \& tuck stitches; weft yarns \& warp yarns; weft \& warp yarns and tuck stitches).

Fig. 3. Manufacturing of thermoplastic composite from knit fabric.

Fig. 4. Tensile properties of thermoplastic composites from knit preforms.

Fig. 5. Flexural properties of thermoplastic composites from knit preforms.

Fig. 6. Impact properties of thermoplastic composites from knit preforms. 


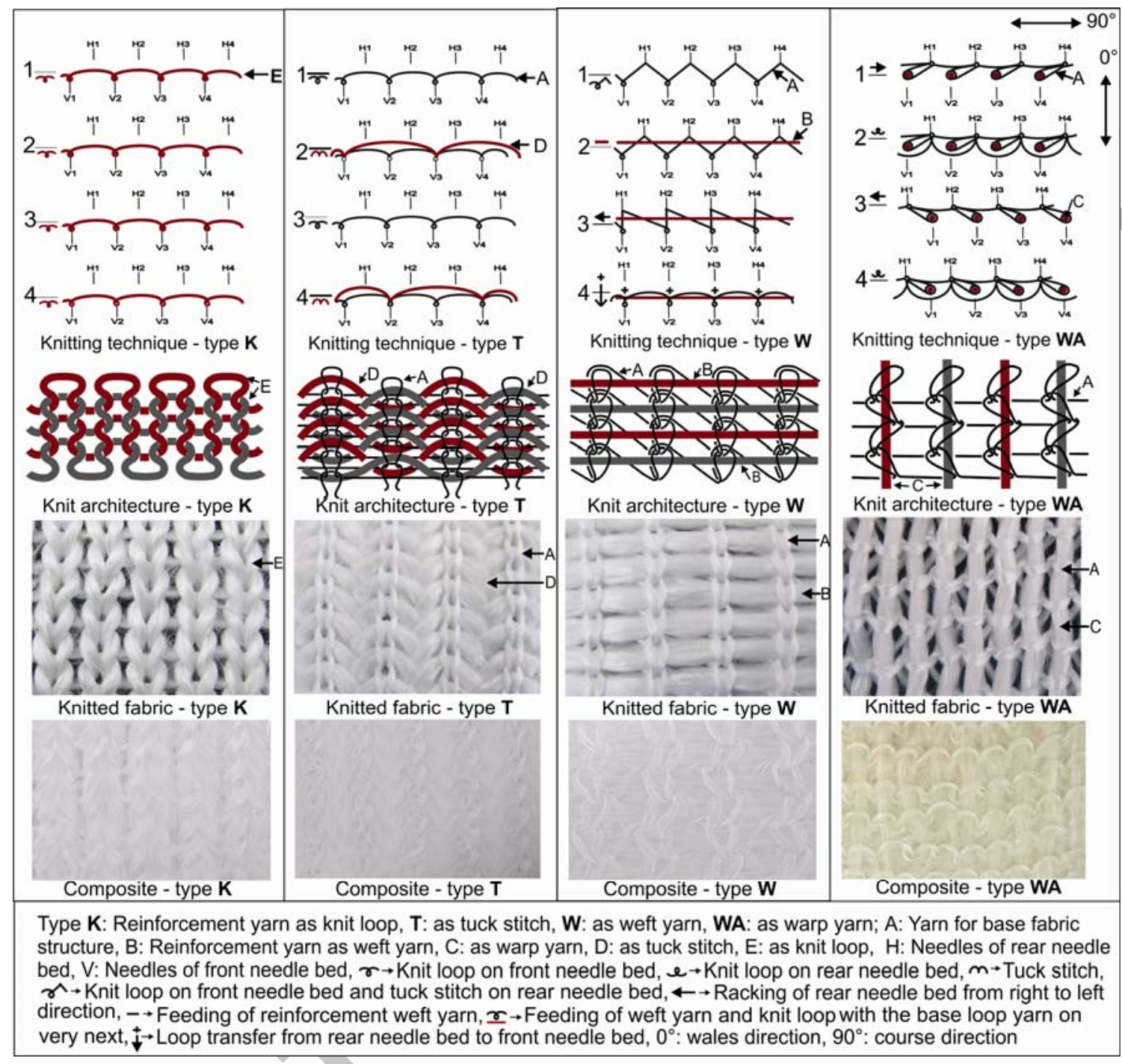




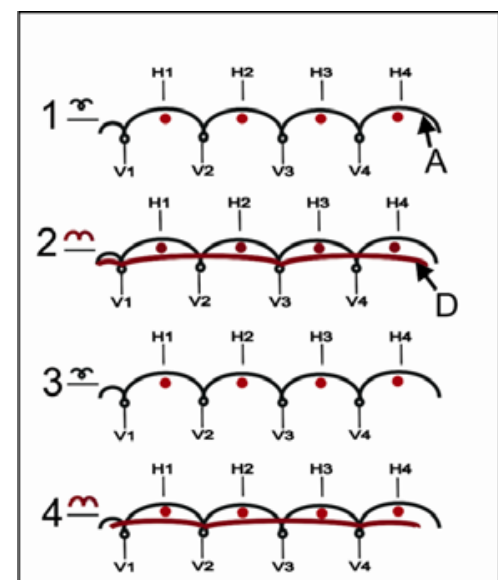

Knitting technique - type WAT

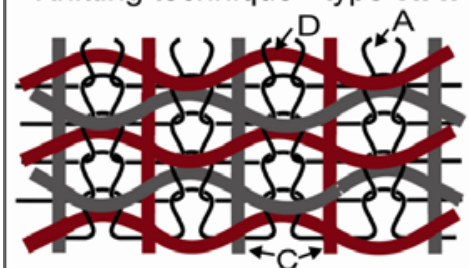

Knit architecture - type WAT

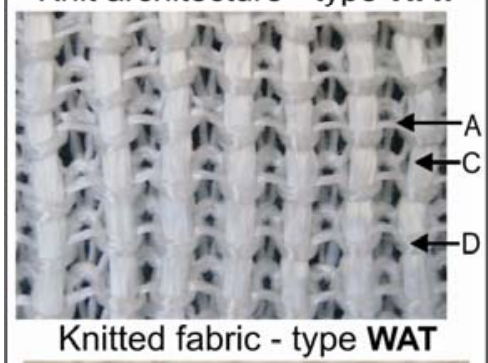

Knitted fabric - type WAT

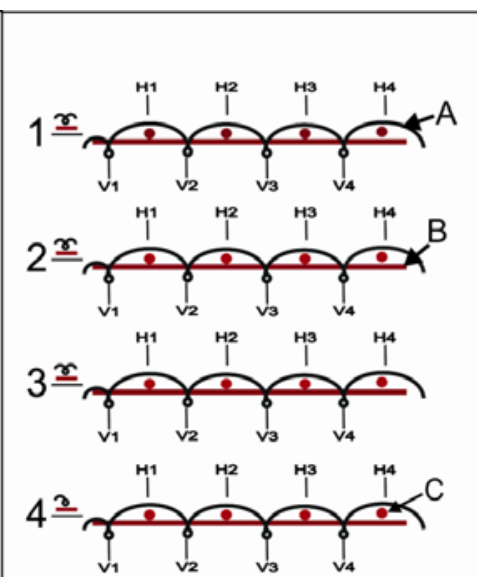

Knitting technique - type WWA

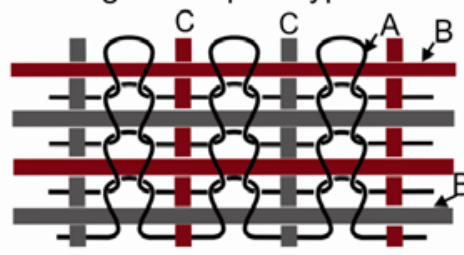

Knit architecture - type WWA

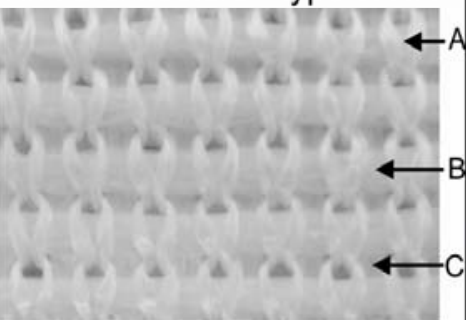

Knitted fabric - type WWA

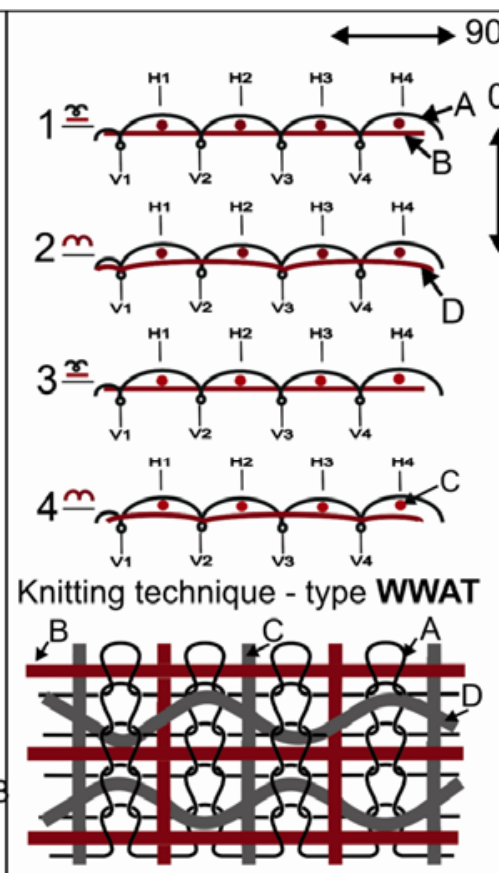

Knit architecture - type WWAT

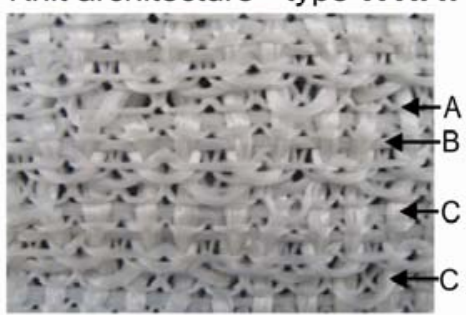

Knitted fabric - type WWAT

Composite - type WAT

Composite - type WWA

Composite - type WWAT

Type WAT: Reinforcement yarn as warp yarn \& as tuck stitch, WWA: as weft yarn \& warp yarn, WWAT: as weft yarn; warp yarn \& as tuck stitch, A: Yarn for base fabric structure, B: weft yarns, C: warp yarn, D: tuck stitch, $\mathrm{H}$ : Needles of rear needle bed, V: Needles of front needle bed, $\boldsymbol{r} \rightarrow$ Knit loop, $\boldsymbol{m} \rightarrow$ Tuck stitch, $\boldsymbol{\gamma} \rightarrow$ Feeding of weft yarn and knit loop with the base loop yarn on very next, $0^{\circ}:$ wales direction, $90^{\circ}:$ course direction 


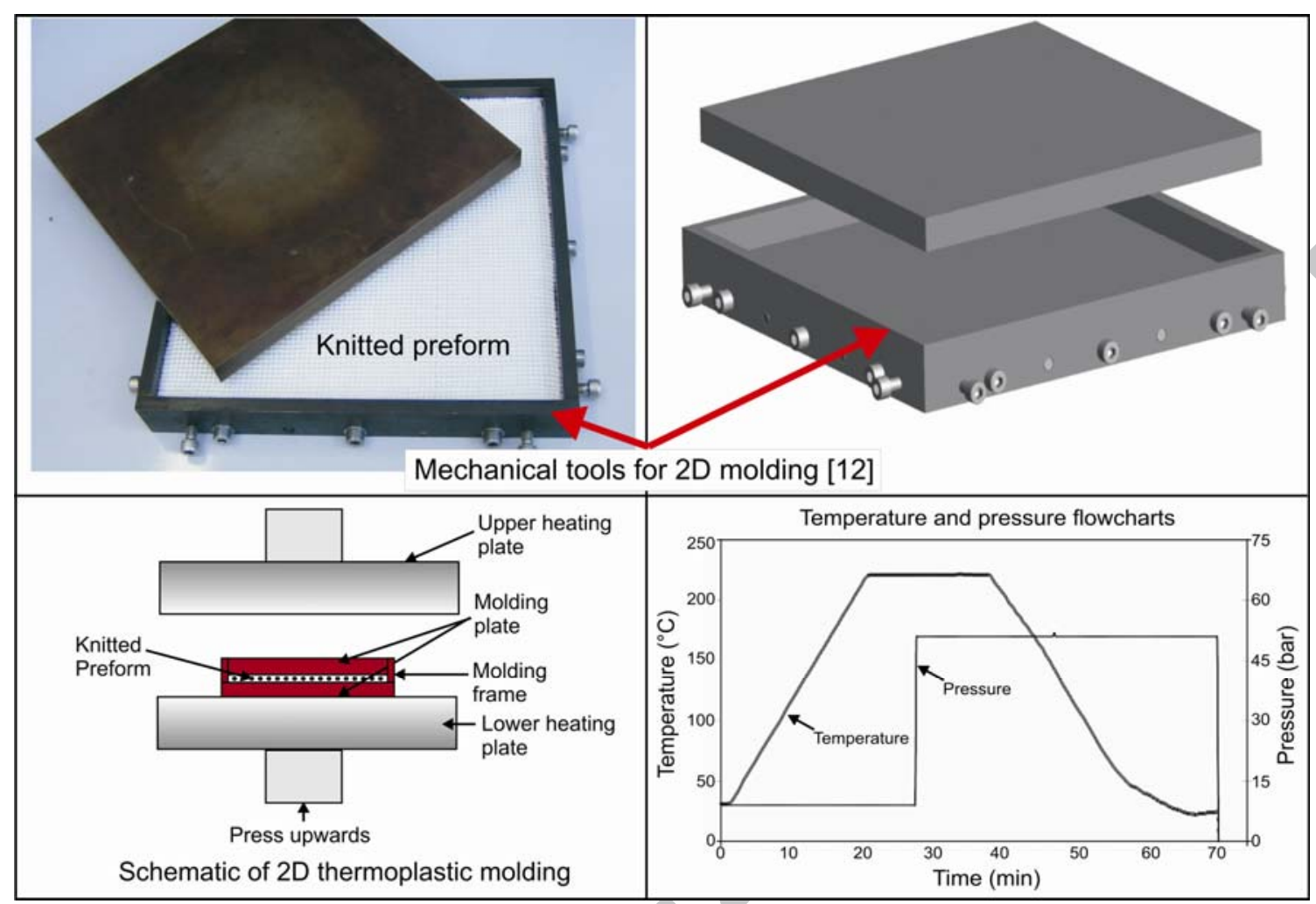




\section{ACCEPTED MANUSCRIPT}
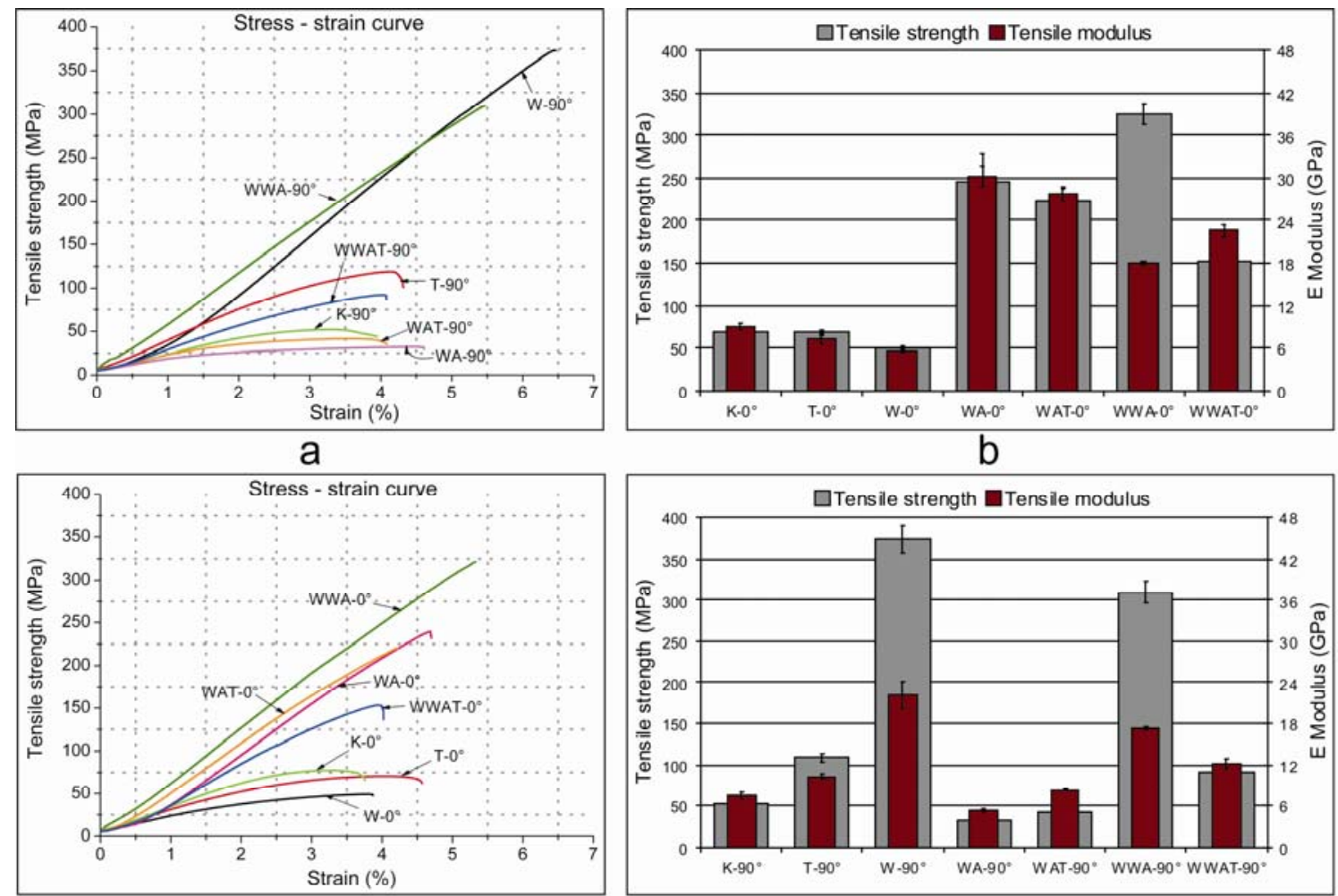

C

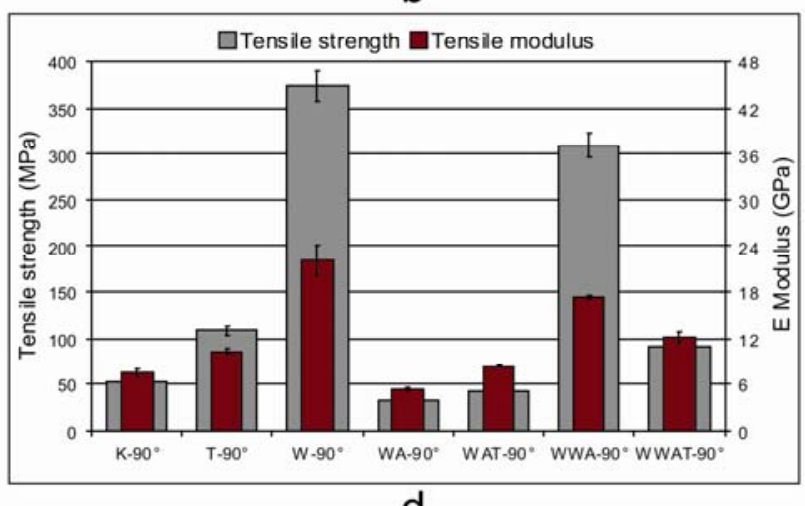

d

$0^{\circ}=$ Test specimen in wales direction, $90^{\circ}=$ Test specimen in course direction 


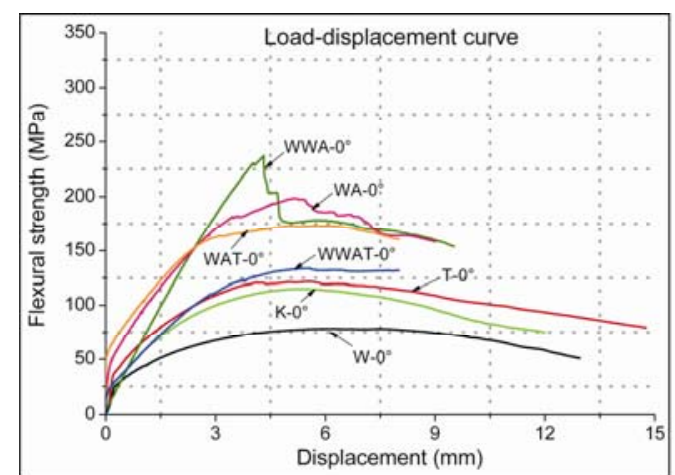

a

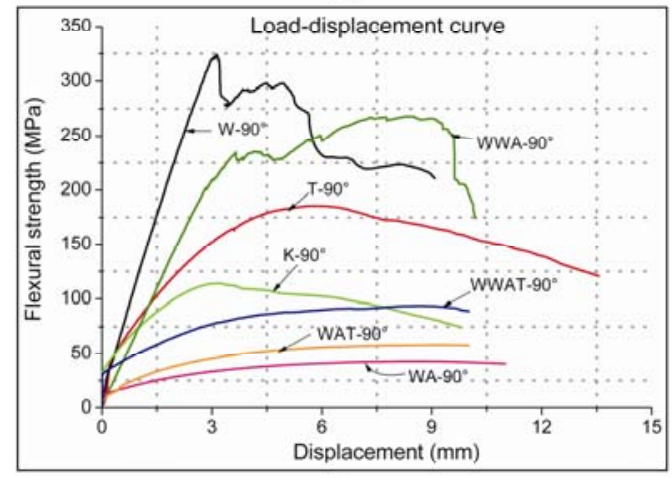

C
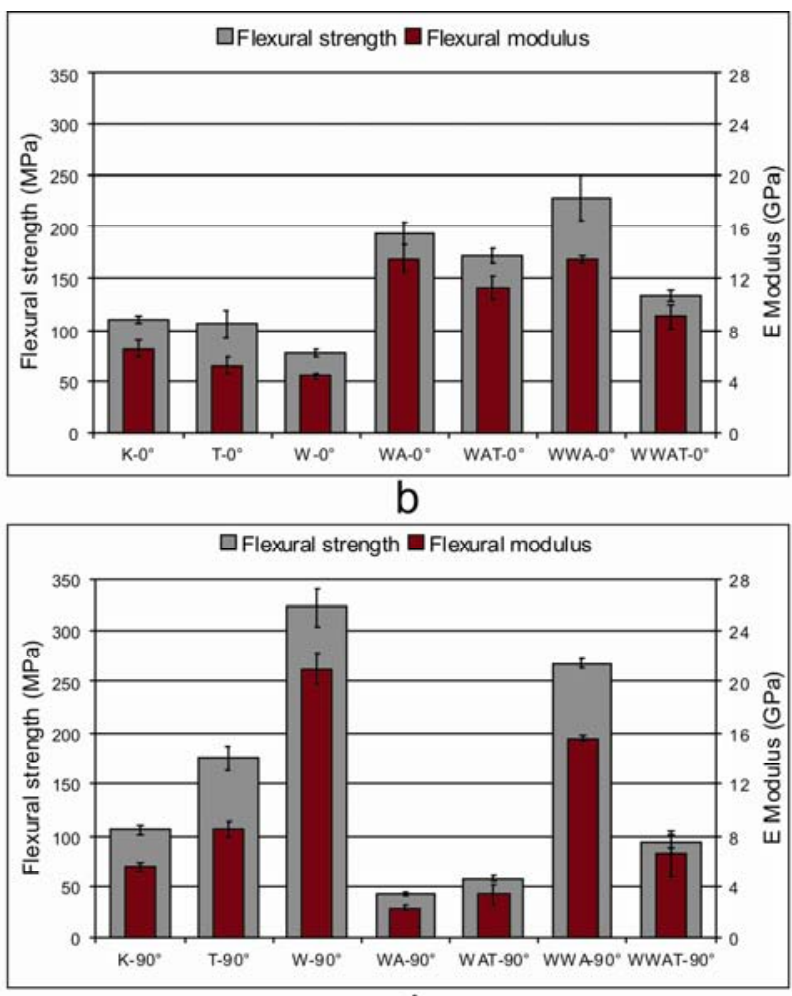

d

$0^{\circ}=$ Test specimen in wales direction, $90^{\circ}=$ Test specimen in course direction 


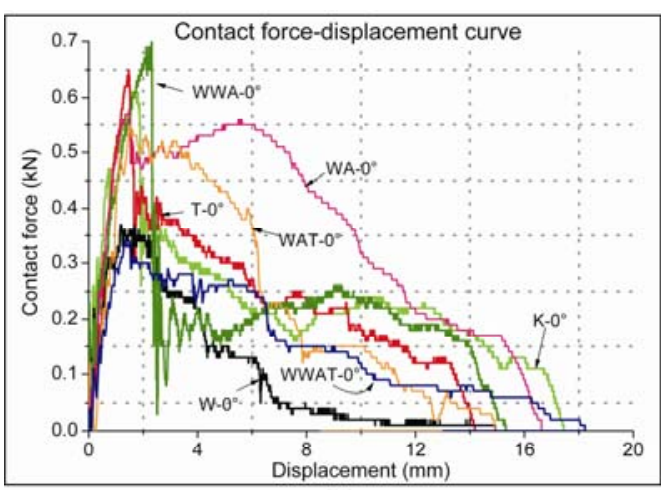

a

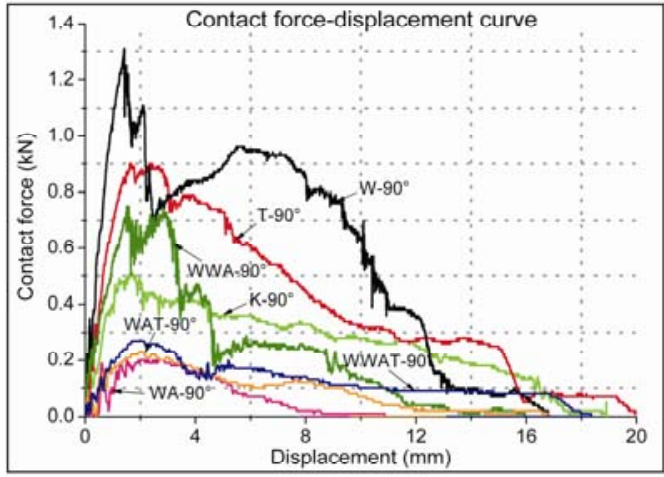

C

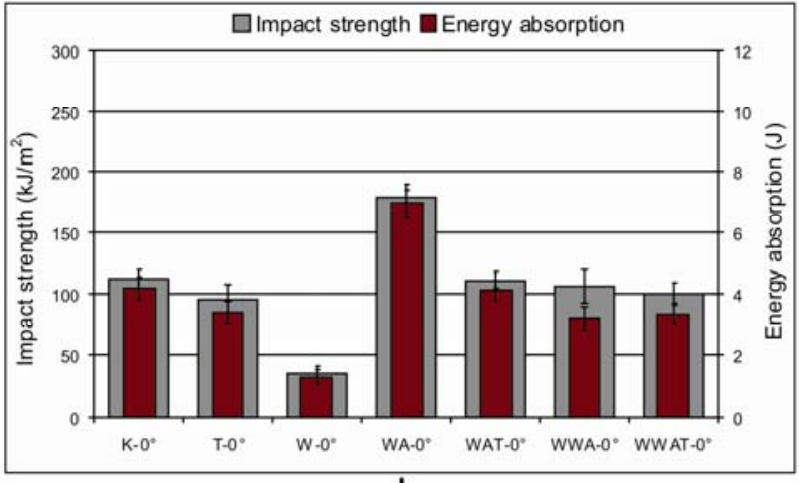

b

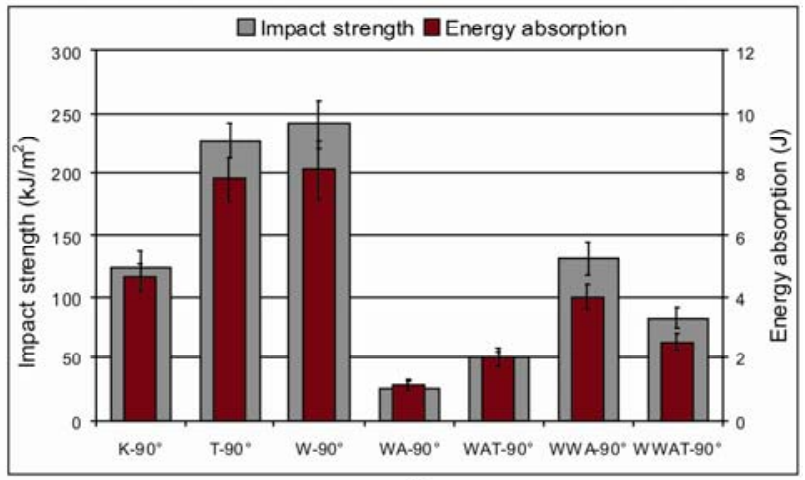

d

$0^{\circ}=$ Test specimen in wales direction, $90^{\circ}=$ Test specimen in course direction 
Table 1 Details of knit fabrics and composites.

\begin{tabular}{|c|c|c|c|c|c|c|c|c|c|c|}
\hline \multirow[b]{2}{*}{ No. } & \multirow{2}{*}{$\begin{array}{l}\text { Reinforcement } \\
\text { yarn integrated in } \\
\text { the knit structures }\end{array}$} & \multicolumn{2}{|c|}{ Yarn feinheit [tex] } & \multicolumn{5}{|c|}{ Fabric specifications } & \multicolumn{2}{|c|}{ Composite data } \\
\hline & & $\begin{array}{l}\text { Base } \\
\text { fabric } \\
\text { yarn }\end{array}$ & $\begin{array}{l}\text { Reinfor- } \\
\text { cement } \\
\text { yarn }\end{array}$ & $\begin{array}{c}\text { Wales } \\
/ \mathrm{cm}\end{array}$ & $\begin{array}{l}\text { Course } \\
/ \mathrm{cm}\end{array}$ & $\begin{array}{l}\text { Loop } \\
\text { length } \\
{[\mathrm{cm}]}\end{array}$ & $\begin{array}{c}\text { Weight } \\
{[\mathrm{kg} /} \\
\left.\mathrm{m}^{2}\right]\end{array}$ & $\begin{array}{c}\text { Fabric } \\
\text { thicknes } \\
\mathrm{s}[\mathrm{mm}]\end{array}$ & $\begin{array}{l}\text { thickness } \\
{[\mathrm{mm}]}\end{array}$ & $\begin{array}{c}\text { Volume } \\
\text { of GF } \\
(\%)\end{array}$ \\
\hline K & Knit loops & - & 1200 & 1.9 & 2.50 & 1.3 & 1.2 & 1.8 & 0.75 & 52.50 \\
\hline $\mathrm{T}$ & Tuck stitchs & 138 & 1200 & 1.0 & 4.10 & 1.9 & 1.3 & 2.0 & 0.81 & 45.20 \\
\hline W & Weft yarns & 138 & 1200 & 1.0 & 3.80 & 1.8 & 0.9 & 1.5 & 0.62 & 44.33 \\
\hline WA & Warp yarns & 138 & 1200 & 2.6 & 3.60 & 1.27 & 0.6 & 0.9 & 0.41 & 40.05 \\
\hline WAT & $\begin{array}{l}\text { Warp yarns \& } \\
\text { Tuck stitches }\end{array}$ & 138 & 1200 & 2.2 & 2.50 & 1.65 & 0.8 & & 0.50 & 44.46 \\
\hline WWA & Warp \& weft yarns & 138 & 1200 & 2.8 & 2.70 & 1.32 & 0.8 & 1.2 & 0.50 & 46.08 \\
\hline WWAT & $\begin{array}{c}\text { Warp yarns, weft } \\
\text { yarns \& } \\
\text { Tuck stitches }\end{array}$ & 138 & 1200 & 2.1 & 2.80 & 1.22 & 0.7 & & 0.45 & 44.31 \\
\hline
\end{tabular}


Table 2 Comparison of mechanical properties of 2D knit composites.

\begin{tabular}{|c|c|c|c|c|c|c|c|}
\hline \multirow{2}{*}{$\begin{array}{l}\text { Integration of } \\
\text { reinforcement } \\
\text { yarns as }\end{array}$} & \multirow{2}{*}{$\begin{array}{l}\text { Direction of } \\
\text { the test } \\
\text { specimen }\end{array}$} & \multicolumn{2}{|c|}{ Tensile properties } & \multicolumn{2}{|c|}{ Flexural properties } & \multicolumn{2}{|c|}{ Impact properties } \\
\hline & & $\begin{array}{c}\text { Tensile } \\
\text { Strength } \\
\text { [MPa] }\end{array}$ & $\begin{array}{c}\mathrm{E} \\
\text { Modulus } \\
{[\mathrm{GPa}]}\end{array}$ & $\begin{array}{c}\text { Flexural } \\
\text { Strength } \\
\text { [MPa] }\end{array}$ & $\begin{array}{c}\mathrm{E} \\
\text { Modulus } \\
{[\mathrm{GPa}]}\end{array}$ & $\begin{array}{c}\text { Impact } \\
\text { Strength } \\
{\left[\mathrm{KJ} / \mathrm{m}^{2}\right]}\end{array}$ & $\begin{array}{c}\text { Energy } \\
\text { absorption } \\
\text { [J ] }\end{array}$ \\
\hline \multirow{2}{*}{$\begin{array}{l}\text { Knit loops } \\
{[\mathrm{K}]}\end{array}$} & Wales $\left[0^{\circ}\right]$ & 69 & 9 & 110 & 6.5 & 112 & 4.2 \\
\hline & Course $\left[90^{\circ}\right]$ & 52 & 7.4 & 106 & 5.5 & 124 & 4.6 \\
\hline \multirow{2}{*}{$\begin{array}{c}\text { Tuck stitches } \\
{[\mathrm{T}]}\end{array}$} & Wales $\left[0^{\circ}\right]$ & 68 & 7.1 & 105 & 5.2 & 96 & 3.4 \\
\hline & Course $\left[90^{\circ}\right]$ & 109 & 10.2 & 175 & 8.5 & 227 & 7.8 \\
\hline \multirow{2}{*}{$\begin{array}{c}\text { Weft yarns } \\
\text { [W] }\end{array}$} & Wales $\left[0^{\circ}\right]$ & 49 & 5.5 & 77 & 4.4 & 35 & 1.3 \\
\hline & Course $\left[90^{\circ}\right]$ & 374 & 22.1 & 323 & 21 & 241 & 8.1 \\
\hline \multirow{2}{*}{$\begin{array}{c}\text { Warp yarns } \\
\text { [WA] }\end{array}$} & Wales $\left[0^{\circ}\right]$ & 246 & 30 & 194 & 13.5 & 179 & 7 \\
\hline & Course $\left[90^{\circ}\right]$ & 32 & 5.3 & 42 & 2.3 & 26 & 1.1 \\
\hline \multirow{2}{*}{$\begin{array}{c}\text { Warp yarns \& } \\
\text { tuck stitches } \\
\text { [WAT] }\end{array}$} & Wales $\left[0^{\circ}\right]$ & 224 & 27.8 & 171 & 11.3 & 111 & 4.1 \\
\hline & Course $\left[90^{\circ}\right]$ & 42 & 8.3 & 57 & 3.3 & 51 & 2 \\
\hline \multirow{2}{*}{$\begin{array}{l}\text { Weft \& warp } \\
\text { yarns [WWA] }\end{array}$} & Wales $\left[0^{\circ}\right]$ & 325 & 18 & 228 & 13.5 & 106 & 3.2 \\
\hline & Course $\left[90^{\circ}\right]$ & 310 & 17.3 & 268 & & 131 & 4 \\
\hline \multirow{2}{*}{$\begin{array}{l}\text { Weft yarns, } \\
\text { warp yarns \& } \\
\text { tuck stitches } \\
\text { [WWAT] }\end{array}$} & Wales $\left[0^{\circ}\right]$ & 152 & 22.6 & 134 & & 100 & 3.4 \\
\hline & Course $\left[90^{\circ}\right]$ & 92 & 12.1 & 94 & 6.5 & 83 & 2.6 \\
\hline
\end{tabular}

